\title{
Research on Multimedia Courseware Design Based on Visual Communication
}

\author{
linlin Nong \\ Institute of information technology of Guilin University of electronic science and technology, Guilin, \\ 541004 , China
}

654899201@qq.com

Keywords: Multimedia; Visual; Convey; Method; Use

\begin{abstract}
The rapid development of today's information technology, multimedia teaching has been very popular. There is a problem worthy to further explore which is visual communication of multimedia teaching. Combined with the actual teaching experience in this paper, according to the basic laws and principles related to teaching visual communication design, multimedia courseware design of visual information to convey the problems were analyzed on the basis of existing studies, summarized and summed general principles and design of multimedia visual information communication design. Finally, combined with the actual teaching, systematic analysis of the elements of visual communication design in multimedia courseware design and production use. In this paper, the application of methods of visual communication was analyzed in-depth, and a specific design was given.
\end{abstract}

\section{Introduction}

The use of multimedia courseware for teaching information transfer includes both visual and auditory, visual type of information which is dominant. Multimedia courseware to strengthen aspects of visual information to convey knowledge and research are essential to ensure accurate and effective multimedia courseware teaching information conveyed. From this paper conducted in-depth study [1].

\section{Visual Fatigue of Visual Communication}

There is a common drawback is that visual fatigue in multimedia courseware. In the process of reading objective visual elements played a certain influence. Such as: multimedia courseware layout, font size, font size, text and background color contrast relations. Font is too large or too small is likely to cause people to read the fatigue, but also pay attention to the selection of multimedia courseware background on a light background with dark text is more lovable. High contrast, anti-white dark background, visually seeps into the background, greatly reducing the text of discernment [2].

Pictures of the design is also very important, the human eye cannot receive a lot of information at the same time, especially in the limited visual conditions, if the picture is designed disorganized, then visual bloat has reached the view cannot be a long time, even when viewing the entries in which the information to visually search large, this page only visually bloated, giving the operation also brought no small trouble.

In addition, multimedia color matching to be reasonable, colors direct impact on the user's visual and psychological feelings, and even affects the mood. A different color scheme will bring a different visual experience, sometimes, in the pursuit of visual impact, we should also pay attention to the impact the color distribution and the distribution of visual brings [3].

\section{Design Concepts and Principles of Multimedia Visual Communication}

Design Concept. Media courseware is the use of visual communication between teachers and students to "see" the form, be transmitted by way of expressing visual language. This approach is based on a 
different geographical, ethnic, age and gender of people passing through the visual information in a variety of images; thereby achieve the purpose of communication between people. Multimedia courseware to achieve the purpose of effective transfer of information, we must consider the humane, innovative, practical, psychological and visual design.

Design Principles. Multimedia teaching is an important carrier of information dissemination, multimedia courseware design process to follow the educational, scientific and technical principles. Because it faces and objects to be achieved for different purposes, we will focus on compulsory technical and artistic unity, the unity of form and content, the multimedia courseware to learn several important elements of graphics, text, color and other visual elements of clever binding [4].

Generally follow the following principles:

- Interface layout should be reasonable, beautiful. Multimedia courseware page layout is reasonable in all the elements of the arrangement of these elements including colors, images, video and text.

- Theme style uniform. Multimedia page should have a relatively stable style screen, to avoid the messy style and unnecessary distraction and cognitive load to the viewer. Color transition should be as unified, forming a visual balance.

- Concise interface. Multimedia courseware is to effectively communicate information for the purpose of teaching, so the page design should always adhere to the principle of clear and concise. Page graphic is too large, too much color, too heavy or word too large, too small, will not only undermine the overall beauty of multimedia courseware, teaching information communicated will result into errors, it becomes less effective.

\section{Multimedia Courseware Design}

The overall design is to first determine the overall style of courseware, courseware sketch determined according to the teaching style to convey the specific content and the target learning object. Then it is finalized and creative arts and design and processing.

Text Design. This paper focuses on the design and layout of text fonts, different font style image forming nowhere to express emotion, to strengthen the text to convey the semantics, reasonable, clear text layout to achieve both fast convey accurate information purposes. From the word shape features analysis, bold, italicized font Founder old, four sides of equal tension; it gives a stable, dignified feel. The italics are more elongated, giving the basic shape upward, downward expansion feeling, body beautiful [5]. From the characteristics of strokes, text, unique style lies in radians and the end of the line strokes. Rough strokes, word blackness great deep sense; fine strokes, bright, soft, female character; straight strokes have a firm sense; different strokes subtle changes in the line-side image corners, can affect the character of the text. As shown in Figure 1:
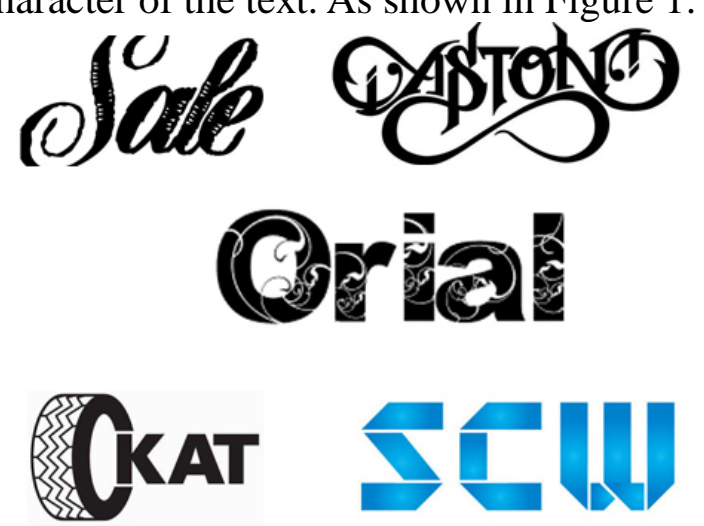

Figure 1.Manifestations of various fonts

Text choreography is by the action of formal artistic treatment, so that the text is reasonable, clear and complete expression, not only compelling, powerful information in turn convey to the reader, the reader needs according to convey content, in order to read. Clever layout, reasonable arrangement of words can make people feel happy, relaxed, and leave a good and solid impression. If a multimedia courseware page text aligned properly, crowded mess, lack of sight to guide the 
flow of the order, will not only affect the beauty of the font itself, is not conducive to effective reading students more difficult to produce a good effect of visual communication. In order to form vivid page visual effects can be considered in terms of style, size, arrangement direction, light and shade and other text, it is necessary to form a lively contrast effect, but also to achieve the unity of the whole composition [6]. As shown in picture 2:

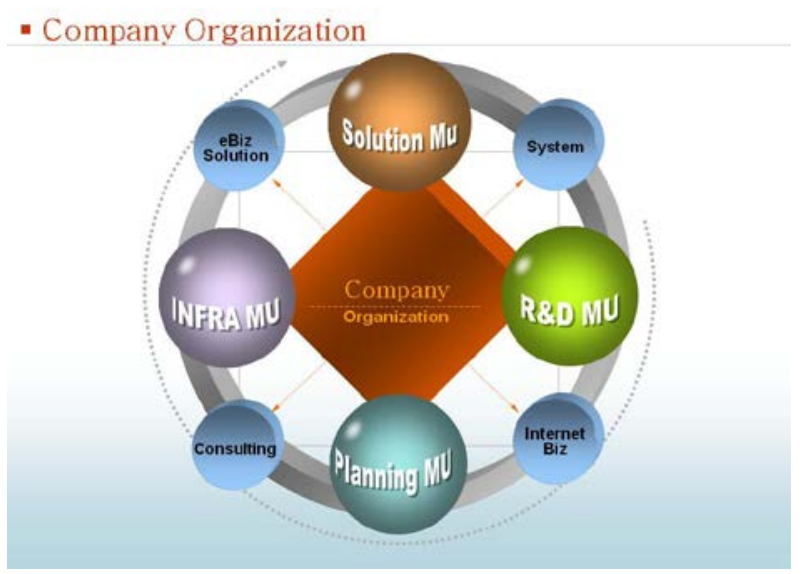

Figure2. Layout of fonts

Image Design. Graphics instead of large blocks of text ramble explanation, simple and clear, people look after a short time they can understand. Abstract graphic from an objective color, shape constraints, fresh, exciting visual images and feelings attract learner's attention, in concise form to facilitate the full sense of the learner understand and remember. For some non-specific image of the learning object or need to show multi-dimensional space or to improve learner imagination, a sense of space for the purpose of teaching, the rational use of graphical abstract thinking can help expand and deepen the understanding of memory.

Abstract and difficult wording will easily lead to visual errors, complex and difficult to understand memory. With graphic representation associated with text opposite may help understand, anything easy. Especially scientific concept is difficult to understand complex textual representation of difficult memories, this time highlighting the advantages of graphics performance. But be sure to pay attention to during selection and design graphic pattern accuracy, the selected or produced by the graphics must be accurate expression of the corresponding teaching content, not to add a graphic to join, so not only does not promote students receiving system, further interfere with and hinder the learner's understanding, distracted, so to convey the effect of teaching information poor. As shown in Figure 3:

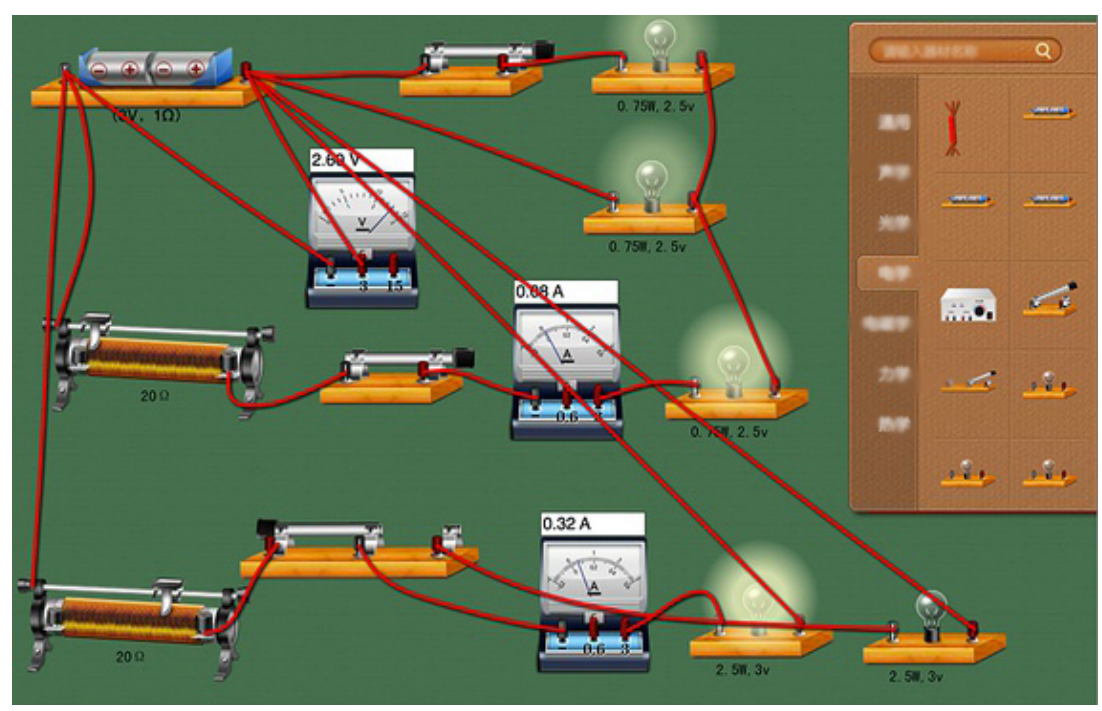

Figure3. Physics experiment

Human information processing along with the role of emotions and feelings, through the creation of graphics-rich content, profound artistic conception, visual expression, can stimulate learners 
corresponding psychological experience and feelings in such situations learners to better understand and digest information content, and can produce beauty. Rich, intuitive image content to help students digest the content, in addition, photography itself is a graphical expression; these pictures can also guide students to observe things and performance point of view, too. As shown in Figure 4:

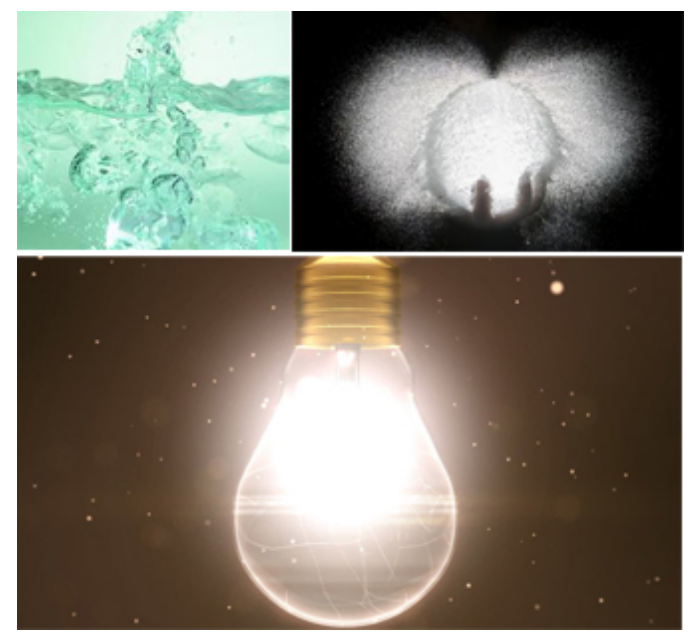

Figure4. Instant of object

Color Design. In visual communication, the color is often conveying a factor that head start, in terms convey efficiency, color graphics to convey more than words to convey and communicate. Compared with other elements of visual communication, color is often used as a first visual language more attractive to the viewer's line of sight, causing the emotional response of the viewer. Therefore, the color design plays a very important in the whole multimedia courseware design position. Multimedia courseware production, color matching should be the first consideration. Color matching should pay attention to the following three questions: First, learners should not feel boring, depressing, so as not to weaken the interest of learners; second, not too fancy, so will distract the attention of students; third, text color and background color to distinguish very well, so as to avoid the learner's visual fatigue.

- Correct choice of color tone. A courseware should have a primary color, and has an overall layout style. Color tone and layout should be selected courseware content, structure, style, consistent color. Multimedia courseware attention to visual communication to convey the main message. Color relations all designs are available through simplified to think of its color matching. Just grab primary and secondary relationship, we can determine the main color, secondary color screen and the main colors, the body must be highlighted, minor body must be set off with the main colors to control the tendency of the entire screen. In a courseware interface should try to control the color about three to four colors, avoid using too much color. The contents with similar functions, module design, balloons and buttons, you should use the same color or similar color, the overall style and maintained before and after use of color consistency. This gives stable, standardized, simple and clear feeling and visual effects.

- Mix color with correct and reasonable to Color design of multimedia courseware, in order to convey a clear message, color visibility is very important. That visibility color perception of color, refers to the extent the strength of color perception. It is a total reaction color hue, lightness, purity contrast, is a person's physiological responses. Color graphics or text from its surroundings can be seen clearly, color comparison chart to the bottom of some can see clearly, some see that some highly visible, and some low visibility.

- Contrast and harmony. Any two colors together will produce contrast, in general, the auxiliary contrast hue, lightness, purity and well-being, and so forward and backward. The degree of contrast can be controlled, it can increase the contrast to make the main highlight, make minor part weaken the contrary, weaken contrast can reach reconciliation; in short, the color difference determines the size of the degree of contrast and harmony. It is shown in Figure 5 and Figure 6: 


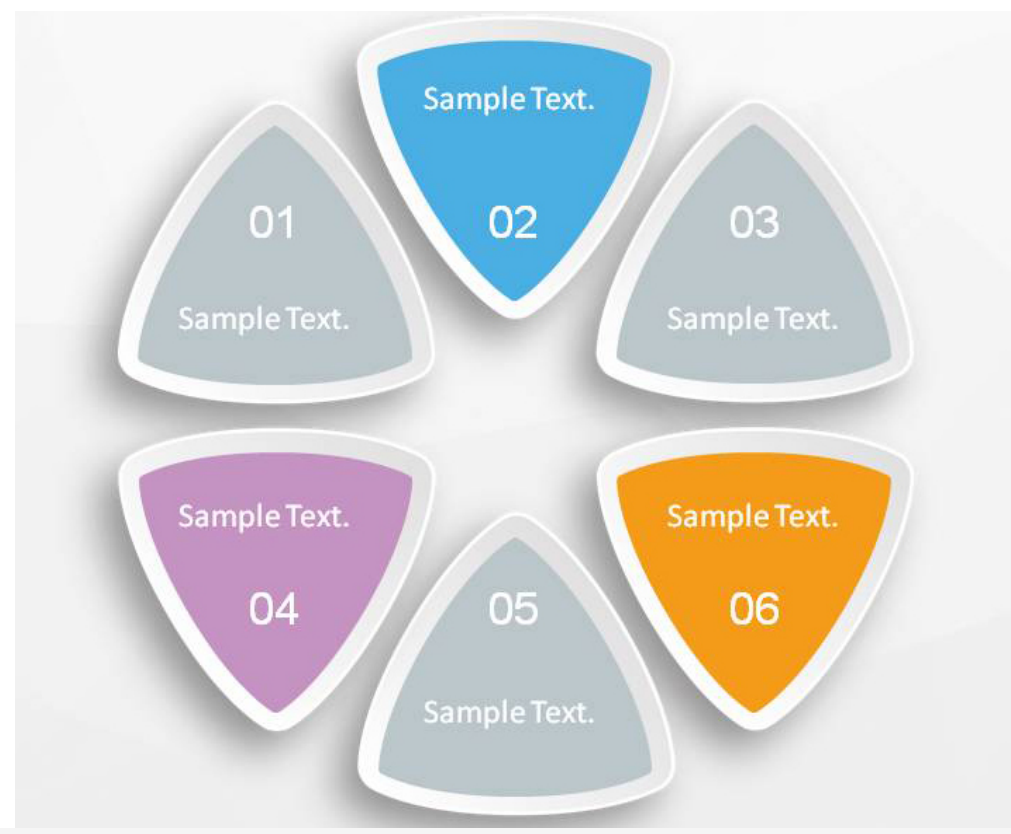

Figure5. Foreground color matching

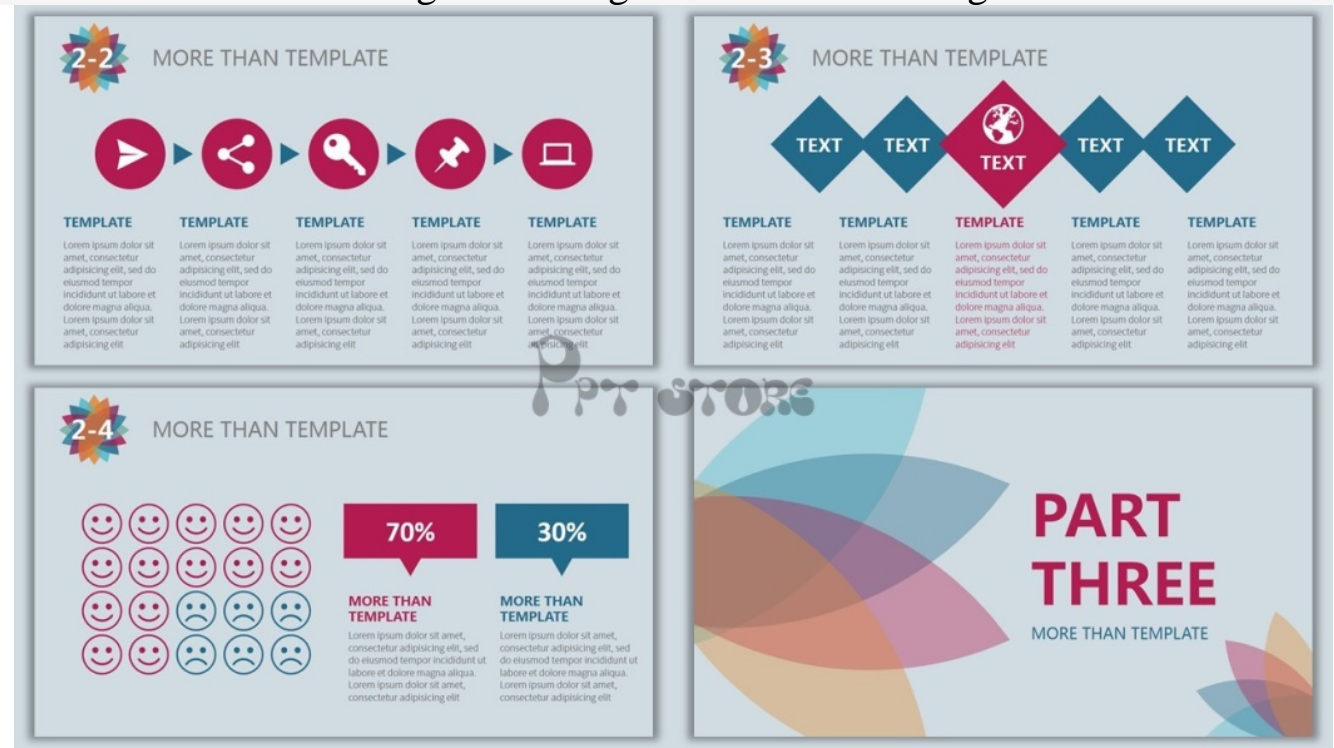

Figure6. Overall design and mix colors

\section{Conclusion}

For learners, teaching obtains information not only from a single of visual elements, but it is showing courseware pages. Therefore, multimedia courseware should pay attention to overall planning page design, highlighting the main, unified style. In the design of multimedia courseware, teaching content as much as possible from the full transfer of information and enhance learner interest, pay attention to two angles, contact the specific characteristics of curriculum, planning and design to create their own courseware, so prominent features, convey information accurately, refreshing the page and rich.

\section{References}

[1] Li Yanzhu. History of Visual Communication Design and Aesthetics [M] Beijing: China Renmin University Press, 2006.

[2] Yu Yonghai, Zhou Xu .Visual Communication Design [M] Beijing: Higher Education Press, 2006. 
[3] Xu Fei. Visual Fatigue of Visual Communication Design Research [D]. Beijing Institute of Clothing, 2014.

[4] Chen Lihua. Relationships Multimedia Educational Technology Used in the Correct Handling [J]. Chinese Adult Education, 2006.

[5] Zhu Shinan. Multimedia Courseware and Teaching Creative [M] Wuhan: Wuhan University Press, 2003.

[6] Zhuchao Xia, Jiang Tengxu. Multimedia Courseware Technology Tutorials [M] Beijing Aeronautics and Astronautics Press, 2008. 